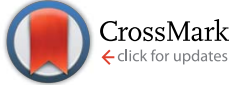

Cite this: RSC Adv., 2017, 7, 7287

Received 5th December 2016 Accepted 9th January 2017

DOI: 10.1039/c6ra27770e

www.rsc.org/advances

\section{Highly efficient triazine/carbazole-based host material for green phosphorescent organic light-emitting diodes with low efficiency roll-off $\dagger$}

\author{
Mingming Hu, ${ }^{a}$ Yang Liu, ${ }^{a}$ Yi Chen, ${ }^{a}$ Wenxuan Song, ${ }^{a}$ Lei Gao, ${ }^{c}$ Haichuan Mu, ${ }^{\text {b }}$ \\ Jinhai Huang ${ }^{d}$ and Jianhua Su*a
}

Two novel host materials, 3-(dibenzo[b,d]furan-4-yl)-9-(4,6-diphenyl-1,3,5-triazin-2-yl)-9H-carbazole (BFTC) and 3-(dibenzo[b,d]thiophen-4-yl)-9-(4,6-diphenyl-1,3,5-triazin-2-yl)-9H-carbazole (BTTC) were designed and synthesized. These two compounds exhibited excellent physical properties with high thermal stabilities and reasonable HOMO-LUMO energy levels. Both of them were applied to fabricate green phosphorescent organic light emitting devices (PhOLEDs) as host materials, and the BTTC based device demonstrated outstanding electroluminescence performance with a maximum current efficiency, maximum power efficiency and external quantum efficiency of $69.3 \mathrm{~cd} \mathrm{~A}^{-1}, 54.2 \mathrm{~lm} \mathrm{~W}^{-1}$ and $21.9 \%$, respectively, suggesting that BTTC is a promising host for green PhOLEDs.

\section{Introduction}

Organic light-emitting devices (OLEDs) are considered as the next generation displays and illumination sources because of their active and large area emissions, high luminous efficiency and low power consumption. ${ }^{1-7}$ It is important to develop efficient host materials for phosphorescent OLEDs with low efficiency roll-off induced by concentration quenching and triplettriplet annihilation..$^{8}$ In general, an appropriate host material is required to satisfy several fundamental properties. Firstly, the triplet energy level $\left(E_{\mathrm{T}}\right)$ of the host should be higher than the dopant to prevent reverse energy transfer from the guest to the host. Secondly, the highest occupied molecular orbitals (HOMOs) and the lowest unoccupied molecular orbitals (LUMOs) of the host are required to match to adjacent material layers to benefit the injection of the hole and electron, so as to reduce the turn-on voltage. In addition, the host is supposed to have good carrier transporting characteristics for effective exciton recombination. Finally, good thermal stability is also expected to form a uniform thin film morphology. ${ }^{9-12}$

\footnotetext{
${ }^{a}$ Key Laboratory for Advanced Materials and Institute of Fine Chemicals, East China University of Science \& Technology, Shanghai 200237, PR China. E-mail: bbsjh@ ecust.edu.cn

${ }^{b}$ Department of Physics, School of Science, East China University of Science and Technology, 130 Meilong Road, Shanghai 200237, PR China. E-mail: hcmu@ecust. edu.cn

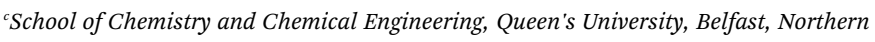
Ireland, UK

${ }^{d}$ Shanghai Taoe Chemical Technology Co., Ltd, Shanghai, PR China

$\uparrow$ Electronic supplementary information (ESI) available: 1H, HRMS and EL spectra under different driving voltages of two materials. See DOI: 10.1039/c6ra27770e
}

In recent years, a great progress of green PhOLEDs based on small molecule materials have been made. ${ }^{13-19}$ Carbazole is a commonly used molecular fragment because its small conjugated system, high triplet energy level and the lone pair electrons in the $\mathrm{N}$ atoms can effectively reduce the splitting of the singlet and triplet energy level, which make carbazole-containing compounds as promising hole-transport materials in OLEDs. ${ }^{20,21}$ Besides, triazine derivatives are widely used as electrontransporting materials due to its high electron affinity. ${ }^{22-25} \mathrm{Su}$ and his coworkers reported a bipolar host material, 2,4,6-tris(3(9H-carbazol-9-yl) phenyl)-1,3,5-triazine, which had low power voltage and high efficiency originated from its small singlettriplet splitting and low LUMO energy level. ${ }^{26}$ Chang and his coworkers developed a dicarbazole-triazine baesd bipolar host material, exhibiting a high glass transition temperature of $134{ }^{\circ} \mathrm{C}$ and triplet energy $\left(E_{\mathrm{T}}=2.67 \mathrm{eV}\right)$, giving a green PhOLEDs doped with $(\mathrm{TPm})_{2} \operatorname{Ir}(\mathrm{acac})$ with maximum efficiencies (EQE) of $20.1 \%$ (76.3 $\mathrm{cd} \mathrm{A}^{-1}$ and $\left.72.7 \mathrm{~lm} \mathrm{~W}^{-1}\right) .{ }^{27}$

Taking the advantage of the carbazole and triazine in the host, two novel host materials, 3-(dibenzo[ $b, d]$ furan-4-yl)-9-(4,6diphenyl-1,3,5-triazin-2-yl)-9H-carbazole (BFTC) and 3-(dibenzo$[b, d]$ thiophen-4-yl)-9-(4,6-diphenyl-1,3,5-triazin-2-yl)-9H-carbazole (BTTC) were designed and synthesized. Besides, the introduction of dibenzo[ $[b, d]$ furan and dibenzo $[b, d]$ thiophen were expected to reduce the oxidation potential, enhance the thermal stability and provide more delocalized electrons for enlarging the HOMO orbital energy level and benefiting the injection and transmission of holes. ${ }^{28}$ The green PHOLEDs based on above mentioned two host materials achieved superior EL performance with the maximum current, power and external quantum efficiency of $69.3 \mathrm{~cd} \mathrm{~A}^{-1}, 54.2 \mathrm{~lm} \mathrm{~W}^{-1}$ and $21.9 \%$, respectively. 


\section{Results and discussion}

\section{Synthesis and characterization}

The synthetic routes for the two compounds are shown in Scheme 1. The key intermediate, 3-(dibenzo[ $b, d]$ furan-4-yl)-9Hcarbazole (3) and 3-(dibenzo[b,d]thiophen-4-yl)-9H-carbazole (5), were synthesized by Suzuki coupling reaction of 3-bromo9H-carbazole (1) and corresponding phenylboronic acid precursors with high yields of $95.3 \%$ and $97.2 \%$, respectively, while the target compounds of BFTC and BTTC were obtained after treating 2-chloro-4,6-diphenyl-1,3,5-triazine and corresponding intermediate in the presence of $\mathrm{NaH}$ in DMF at room

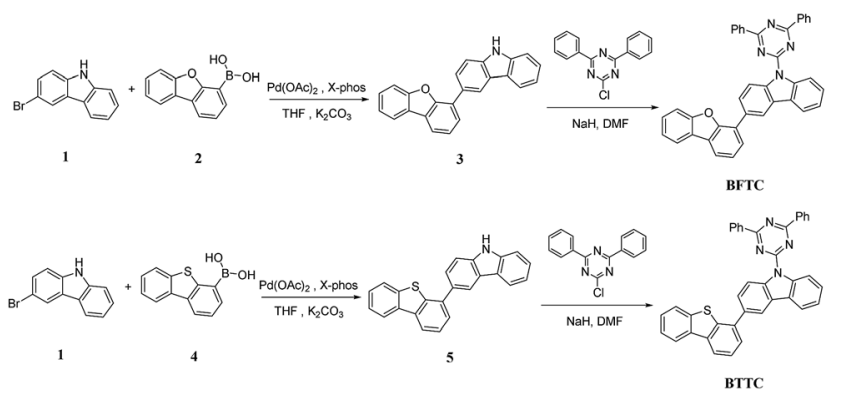

Scheme 1 Synthetic routes of the compounds.
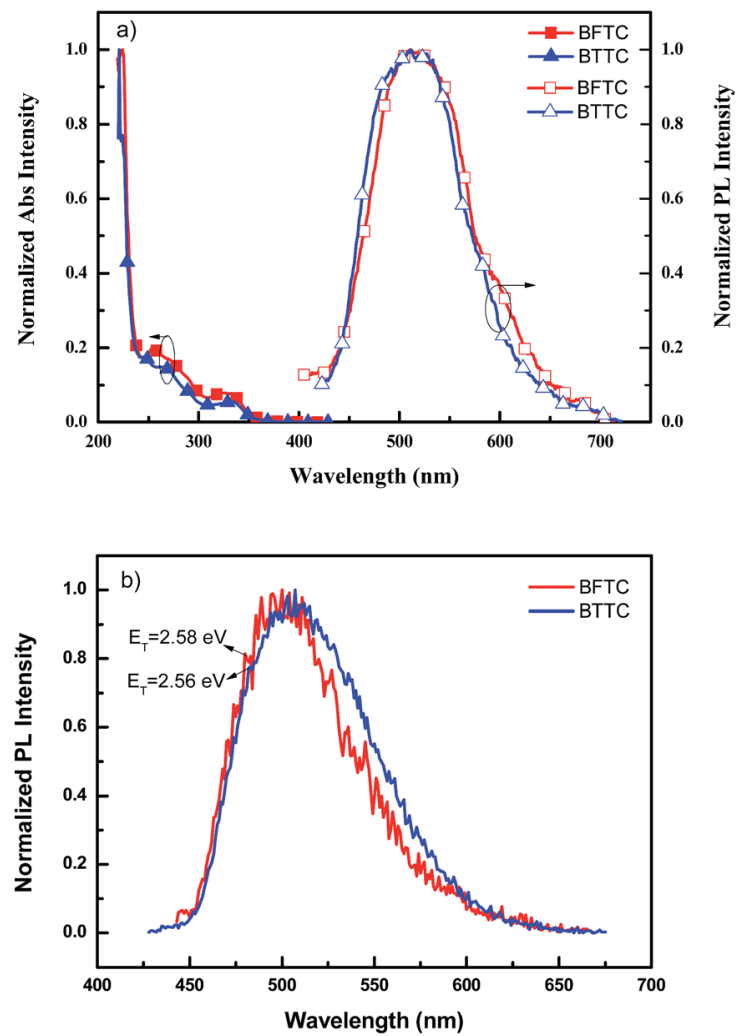

Fig. 1 (a) Normalized UV-vis absorption and fluorescence emission spectra of the compounds in dichloromethane solution at room temperature; (b) phosphorescence spectra in a frozen 2-methyltetrahydrofuran at $77 \mathrm{~K}$. temperature with high yield of $93.5 \%$ and $89.7 \%$, respectively. The molecular structures of two intermediates were confirmed by ${ }^{1} \mathrm{H}$ NMR. Additionally, the molecular structure of the final compounds can be confirmed by elemental analyses and highresolution mass spectrometry (HRMS).

\section{Photophysical properties}

Fig. 1(a) displays the UV-vis absorption and fluorescence spectra of the two compounds in dichloromethane (DCM) solution, and the detailed data are presented in Table 1. BFTC and BTTC show almost identical absorption peaks with only a $5 \mathrm{~nm}$ difference in peak wavelength. The strong absorption peak around $260 \mathrm{~nm}$ can be assigned to the $\pi-\pi^{*}$ transition of the compounds, and the additional absorption peak around $330 \mathrm{~nm}$ can be attributed to the $n-\pi^{*}$ transition of the carbazole moiety. ${ }^{29}$ The optical energy bandgaps $\left(E_{\mathrm{g}}\right)$ of the two compounds estimated from the onset of the absorption spectra are determined to be $3.44 \mathrm{eV}$ and $3.53 \mathrm{eV}$, respectively. The maximum PL emission wavelengths of the two compounds are both observed at $511 \mathrm{~nm}$. Furthermore, the triplet energies $\left(E_{\mathrm{T}}\right)$ estimated from the phosphorescence spectrum in 2-methyl-tetrahydrofuran at $77 \mathrm{~K}$ are $2.58 \mathrm{eV}$ for BFTC, and 2.56 for BTTC. Such high dibenzofuran substituent has a higher $E_{\mathrm{T}}$ than the dibenzothiophene substituent. Therefore, the two compounds with high bandgaps and triplet energy levels make them promising host materials for green PhOLEDs.

\section{Thermal properties}

The thermal properties of the two compounds were investigated by thermogravimetric analysis (TGA) and differential scanning calorimetry analysis (DSC) under nitrogen atmosphere. As shown in Fig. 2 and Table 1, the TGA measurement reveals their high thermal-decomposition temperatures $\left(T_{\mathrm{d}}\right.$, corresponding to $5 \%$ weight loss) of $398{ }^{\circ} \mathrm{C}$ for BFTC and $452{ }^{\circ} \mathrm{C}$ for BTTC, respectively. We observed a well-defined melting peak of $278{ }^{\circ} \mathrm{C}$ for BFTC and $280{ }^{\circ} \mathrm{C}$ for BTTC, while the endothermic glass transition temperature $\left(T_{\mathrm{g}}\right)$ of both two compounds are not observed even in the second scan by the DSC. From the data above, new host materials exhibit high thermal ability because of their high molecule weight especially for BTTC, which is favorable to form stable films surface morphology.

\section{Electrochemical properties}

The electrochemical behaviors of the two compounds were determined by cyclic voltammetry (CV) using a $\mathrm{Fc} / \mathrm{Fc}^{+}$couple as the internal reference. As shown in Fig. 3, all the CV curves exhibit irreversible oxidation process in DCM solution, and the onset irreversible oxidation process in DCM solution, and the onset potentials are $0.86,0.89 \mathrm{~V}\left(v s . \mathrm{Fc} / \mathrm{Fc}^{+}\right)$for BFTC and BTTC, respectively. Compared to the BTTC, the electron-delocalization of BFTC is larger by replacing the dibenzothiophene ring with dibenzofuran ring, rendering easier oxidation. Their HOMO levels, which are $-5.26 \mathrm{eV}$ for BFTC and $-5.29 \mathrm{eV}$ for BTTC, respectively, are determined from the onset potentials while ferrocene/ferrocenium $\left(\mathrm{Fc} / \mathrm{Fc}^{+}\right)$was applied as the internal standard. Subsequently, based on the optical energy gaps and 
Table 1 Physical properties of BFTC and BTTC

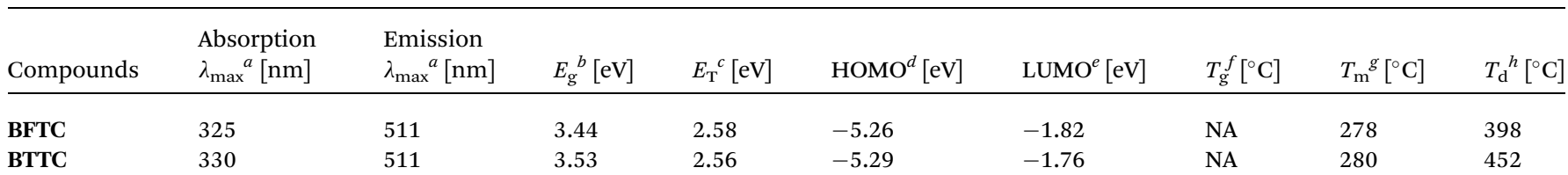

${ }^{a}$ Measured in dichloromethane at a concentration of $1.0 \times 10^{-5}$ and excited by $335 \mathrm{~nm} .{ }^{b}$ Estimated from onset of the absorption spectra $\left(E_{\mathrm{g}}=\right.$ $\left.1241 / \lambda_{\text {onset }}\right) .{ }^{c}$ Estimated from the phosphorescence spectrum in 2-methyl-tetrahydrofuran at $77 \mathrm{~K} .{ }^{d}$ The HOMO energy level was determined from cyclic voltammetry $\left(E_{\mathrm{HOMO}}=-4.4-E_{\mathrm{ox}}\right) .{ }^{e}$ The LUMO energy level was calculated by the equation: $E_{\mathrm{LUMO}}=E_{\mathrm{HOMO}}+E_{\mathrm{g}} .{ }^{f}$ Measured by DSC, NA: no available. ${ }^{g} T_{\mathrm{m}}$ : melting temperature. ${ }^{h} T_{\mathrm{d}}$ : decomposition temperature at $5 \%$ weight loss.

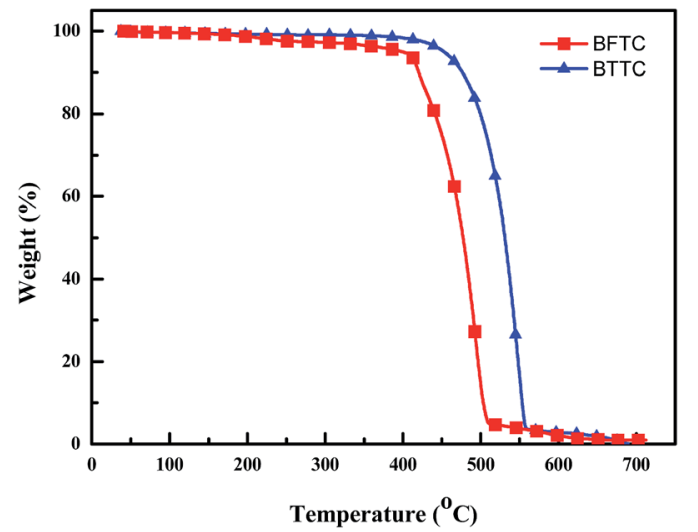

Fig. 2 TGA traces of the two compounds.

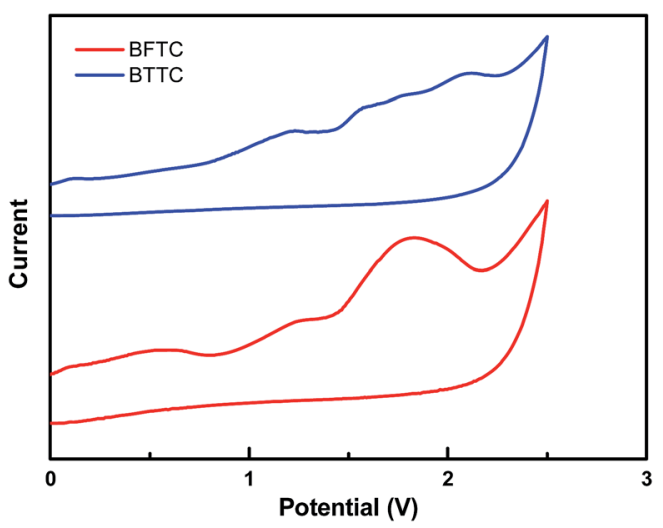

Fig. 3 Oxidation behaviors of the two compounds in $\mathrm{CH}_{2} \mathrm{Cl}_{2}$ solution containing $0.1 \mathrm{M} \mathrm{TBAPF}_{6}$ electrolytes, scanning rate: $100 \mathrm{mV} \mathrm{s}^{-1}$.

HOMO levels, their LUMO levels were deduced to be $-1.82 \mathrm{eV}$ for BFTC and $-1.76 \mathrm{eV}$ for BTTC.

\section{Theoretical calculation}

To further understand the electronic structural properties corresponding to the molecular level of the two compounds, the frontier molecular orbital energy levels were calculated by density functional theory (DFT) at the B3LYP/6-31G level. Fig. 4 shows that the lowest unoccupied molecular orbital (LUMO) energy levels of both two compounds are mainly located at the 2,4-diphenyl-1,3,5-triazine moiety due to the stronger

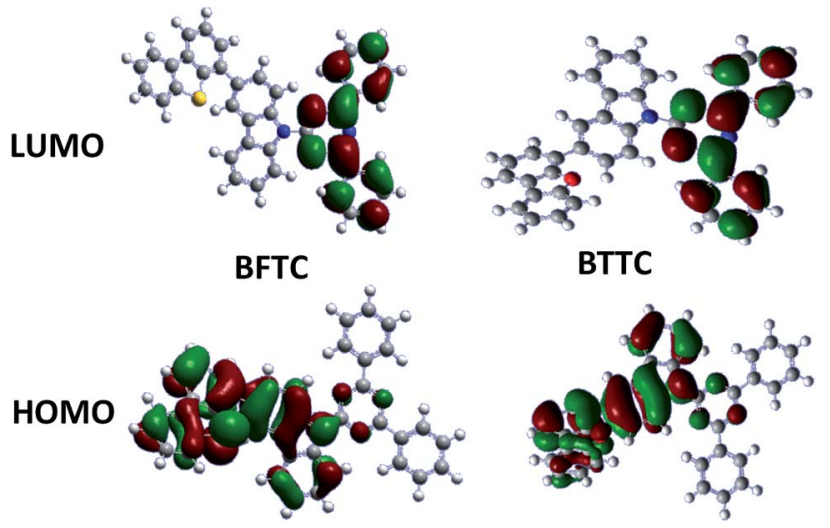

Fig. 4 The molecular orbital surface of the HOMO and LUMO levels for the two compounds.

electronegativity of triazine core. The highest occupied molecular orbital (HOMO) levels of BFTC are distributed among the electrondonating 3-(dibenzo[ $b, d]$ furan-4-yl)-9H-carbazole moiety, while BTTC are mainly located at the 3 -(dibenzo[ $[b, d]$ thiophen-4-yl)-9carbazole moiety, which reveals a desirable separation of HOMOs and LUMOs benefiting for the transporting balance of holes and electrons. Unconjugated fluorene moiety contributes to the effective separation of the electron density of the HOMO and LUMO, which induces a high $E_{\mathrm{T}}{ }^{30}$

\section{Electroluminescence of PHOLEDs}

To evaluate the properties of the two compounds as host materials, the device configuration of [ITO/PEDOT:PSS $(6 \mathrm{~nm}) /$ TAPC (35 nm)/TCTA $(5 \mathrm{~nm}) /$ host: $\operatorname{Ir}(\text { ppy })_{3}(20 \mathrm{~nm}, 8 \mathrm{wt} \%) /$ TPBi $(35 \mathrm{~nm}) / \mathrm{LiF}(1 \mathrm{~nm}) / \mathrm{Al}(80 \mathrm{~nm})]$ were fabricated. Here, the emitting layer (EMT) was composed of $8 \mathrm{wt} \% \operatorname{Ir}(\mathrm{ppy})_{3}$ doped into the host materials. ITO and LiF/Al were used as the anode and composite cathode, respectively. Poly(3,4-ethylene dioxythiophene)/poly(styrenesulfonate) (PEDOT:PSS) was employed as the hole injection layer, 4,4'-(cyclohexane-1,1-diyl) bis( $N, N$-di-p-tolylaniline) (TAPC) served as hole-transporting layer (HTL), tris(4-(9H-carbazol-9-yl)phenyl)amine (TCTA) was used as electron-blocking layer (EBL), and 1,3,5-tris(1-phenyl$1 H$-benzo[ $d]$ imidazol-2-yl)benzene (TPBi) was employed as holeblocking layer (HBL) and electron-transporting layer (ETL). The device and the related HOMO and LUMO energy levels of these materials in devices are shown in Fig. 5. In addition, the current 

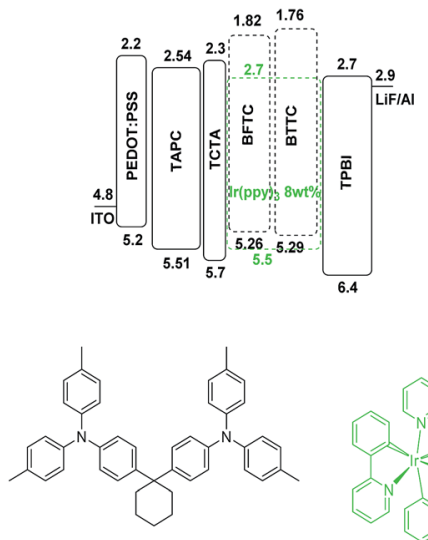

TAPC

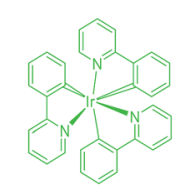

$\operatorname{Ir}(\text { ppy })_{3}$
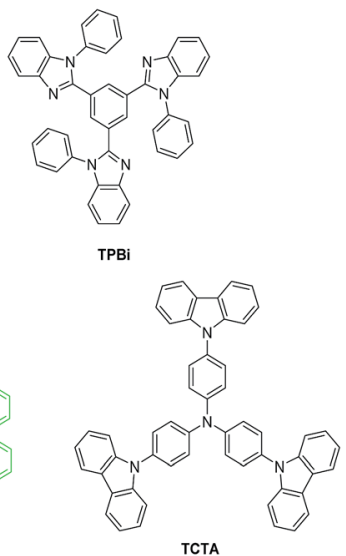

TCTA
Fig. 5 The energy level diagram of the materials in devices.

density-voltage-luminance $(J-V-L)$ characteristics, efficiencies and EL spectra for devices are shown in Fig. 6, and their key performances results are summarized in Table 2.

As revealed in Fig. 6 and Table 2, the turn-on voltages are $3.3 \mathrm{eV}$ for BFTC and $3.4 \mathrm{eV}$ for BTTC, respectively, at a luminance of $1 \mathrm{~cd} \mathrm{~m}^{-2}$. The low turn-on voltages of two devices should result from the matched HOMO and LUMO energy levels of two hosts with their adjacent layers, TCTA and TPBi, which is favorable for the injection of the hole and electron, so as to profit the recombination of hole and electron in emitting layer. The maximum luminance of BFTC is $17241 \mathrm{~cd} \mathrm{~m}^{-2}$, and 24535 cd $\mathrm{m}^{-2}$ for BTTC, respectively. It can be found that both the luminance and current density of BTTC are higher than BFTC, suggesting BTTC as a more promising host for green PhOLEDs. The current/power efficiency-luminance characteristics are shown in Fig. 6(b). The BTTC based device exhibits more efficient electroluminescence performance with the demonstrated respective current and power efficiency of $69.3 \mathrm{~cd} \mathrm{~A}^{-1}$ and 54.2 $\operatorname{lm~} \mathrm{W}^{-1}$ compared to those of $63.1 \mathrm{~cd} \mathrm{~A}^{-1}$ and $45.2 \mathrm{~lm} \mathrm{~W}^{-1}$ for BFTC. The high efficient performance is caused by its approximate LUMO energy levels with the TPBi, which is beneficial for electron transportation. As showed in Fig. 6(c), the maximum external quantum efficiency of $21.9 \%$ is achieved by BTTC, while $19.7 \%$ for BFTC. Both two compounds show high electroluminescence efficiency even at a high luminance, and only slight efficiency roll-off over a wide range of luminance is observed. Importantly, a high efficiency of $50.5 \mathrm{~cd} \mathrm{~A}^{-1}, 22.3 \mathrm{~lm}$ $\mathrm{W}^{-1}(15.7 \% \mathrm{EQE})$ even at $10000 \mathrm{~cd} \mathrm{~m}^{-2}$ was also obtained for BTTC. From the EL spectra showed in Fig. 6(d), green light emissions with the respective emission peaks of 507 and $508 \mathrm{~nm}$ (the corresponding CIE coordinates of $(0.28,0.61)$ and $(0.30,0.60)$ at $6 \mathrm{~V})$ for two compounds based device are proved. We believe that the electroluminescence performance will be further improved via the optimizing device configurations.

To further verify the difference in the charge transport of two compounds, hole and electron only devices were fabricated with the structure of [ITO/PEDOT:PSS $(5 \mathrm{~nm}) /$ TAPC $(5 \mathrm{~nm}) /$ host $(60$ $\mathrm{nm}) / \mathrm{TAPC}(5 \mathrm{~nm}) / \mathrm{LiF}(1 \mathrm{~nm}) / \mathrm{Al}(80 \mathrm{~nm})]$ for the for the hole, and [ITO/TmPyPB (5 nm)/host (60 nm)/TmPyPB (5 nm)/LiF (1 nm)/Al
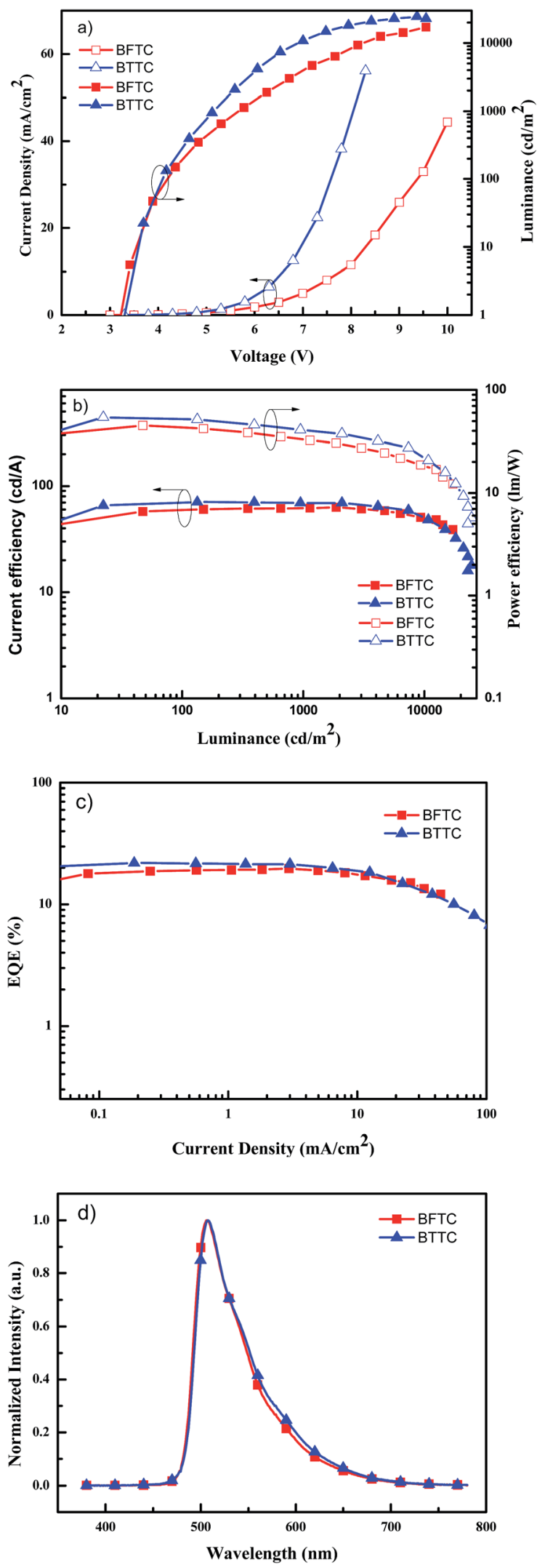

Fig. 6 (a) Current density-voltage-luminance $(I-V-B)$ characteristics; (b) current and power efficiency; (c) external quantum efficiency (EQE) versus current density; (d) EL spectra at $6 \mathrm{~V}$ of green PhOLEDs. 
Table 2 Characteristics of OLEDs with BFTC and BTTC host materials

\begin{tabular}{|c|c|c|c|c|c|c|c|}
\hline Device & Host & $V_{\mathrm{on}}{ }^{a}[\mathrm{~V}]$ & $L_{\max }^{b}\left[\mathrm{~cd} \mathrm{~m}^{-2}\right]$ & $\eta_{\mathrm{c}}^{c}\left[\mathrm{~cd} \mathrm{~A}^{-1}\right]$ & $\eta_{\mathrm{p}}^{c}\left[\operatorname{lm~} \mathrm{W}^{-1}\right]$ & $\eta_{\mathrm{ext}}^{c}[\%]$ & $\operatorname{CIE}_{(x, y)}^{d}$ \\
\hline A & BFTC & 3.3 & 17241 & $63.1,61.9,50.1$ & $45.2,32.4,18.5$ & $19.7,19.3,15.5$ & $(0.28,0.61)$ \\
\hline B & BTTC & 3.4 & 24535 & $69.3,69.2,50.5$ & $54.2,41.0,22.3$ & $21.9,21.4,15.7$ & $(0.30,0.60)$ \\
\hline
\end{tabular}

${ }^{a}$ Turn-on voltage to give a luminance of $1 \mathrm{~cd} \mathrm{~m}^{-2} \cdot{ }^{b} L_{\text {max }}$ : maximum luminance. $\eta_{\mathrm{c}}$ : current efficiency. $\eta_{\mathrm{p}}$ : power efficiency. $\eta_{\text {ext }}$ : external quantum efficiency. ${ }^{c}$ Order of measured values: maximum, then at $1000 \mathrm{~cd} \mathrm{~m}^{-2}$ and $10000 \mathrm{~cd} \mathrm{~m}^{-2}$. ${ }^{d}$ Measured form the EL spectra at $6 \mathrm{~V}$ by inverting chromaticity coordinates on the CIE 1931 diagram.

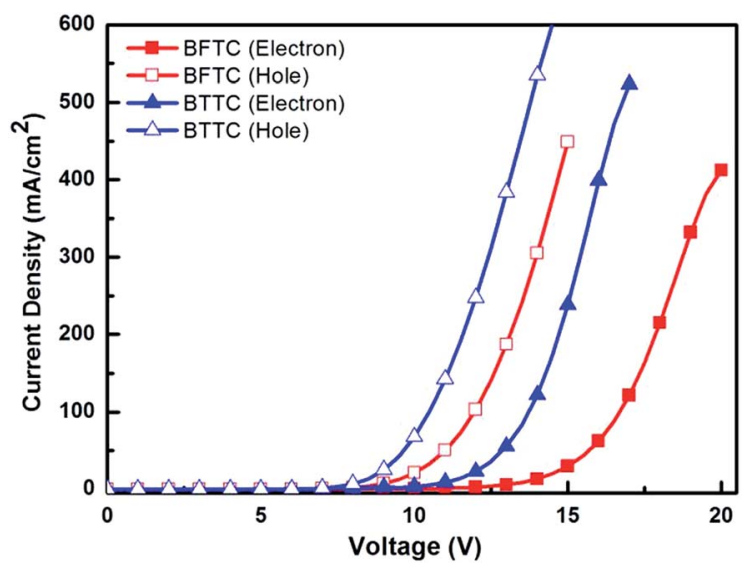

Fig. 7 Current density-voltage curves of hole and electron only devices.

$(80 \mathrm{~nm})]$ for the electron. The $J-V$ characteristics of the hole-only and electron-only devices are shown in Fig. 7.

Clearly from Fig. 7, the currents for the hole only device of BTTC are the highest, and the appropriate hole and electron current densities in both the hole and electron only devices demonstrates good and balanced charge transport, which provides the evidence to support its superior EL performance compared to that of the BFTC. On the other hand, BFTC shows a slightly higher hole current density compared to its poor electron current density, which leads to the unbalanced bipolar transporting ability and then the unsatisfactory EL performance obtained.

\section{Experimental section}

\section{General information}

All the reagents and solvents used for the synthesis or measurements were commercially available without further purification. The ${ }^{1} \mathrm{H}$ NMR spectra was recorded on a Brucker AM 400 spectrometer with tetramethylsilane as an internal reference. Molecular masses were determined by a Waters LCT premier XE spectrometer. Elemental analyses were performed on a Vario EL-III microanalyzer. Thermogravimetric analysis (TGA) was performed using a PerkinElmer Pyris Diamond instrument, and the thermal stability of the samples under a nitrogen atmosphere was determined by measuring their weight loss, at a heating rate of $10^{\circ} \mathrm{C} \mathrm{min}^{-1}$ from 40 to $700{ }^{\circ} \mathrm{C}$. The differential scanning calorimetry analysis (DSC) was obtained by a DSC Q2000 instrument under a nitrogen atmosphere.
UV-vis absorption spectra were recorded on a Varin Cary 500 recording spectrophotometer with baseline correction. Photoluminescence (PL) spectra were recorded on a Varian-Cary fluorescence spectrophotometer. Cyclic voltammetric studies of the compounds in oxidation processes were carried out in nitrogenpurged dichloromethane (DCM) solution at room temperature by a Versastar II electrochemical workstation. The conventional three-electrode configuration consists of a glassy carbon working electrode, a platinum wire counter electrode, and a regular calomel reference electrode in saturated $\mathrm{KCl}$ solution. $\mathrm{Bu}_{4} \mathrm{NPF}_{6}$ $(0.1 \mathrm{M})$ was employed as a supporting electrolyte, and ferrocenium/ferrocene $\left(\mathrm{Fc} / \mathrm{Fc}^{+}\right)$was served as an internal standard. The highest occupied molecular orbital (HOMO) energy levels $(\mathrm{eV})$ of these compounds were calculated according to the formula: $-\left[4.8 \mathrm{eV}+\left(E_{\text {onset,oxidation }}-E_{1 / 2\left(\mathrm{Fc} / \mathrm{Fc}^{\dagger}\right)}\right)\right]$.

\section{Material synthesis}

The synthetic routes for the two compounds are shown in Scheme 1.

3-(Dibenzo[b,d]furan-4-yl)-9H-carbazole (3). A mixture of 3bromo-9H-carbazole $(1.0 \mathrm{~g}, 4.06 \mathrm{mmol})$, dibenzo[b,d]furan-4ylboronic acid $(0.95 \mathrm{~g}, 4.47 \mathrm{mmol})$, tetrahydrofuran $(20 \mathrm{~mL})$, potassium carbonate $(2 \mathrm{M}, 20 \mathrm{~mL})$, and $\mathrm{Pd}\left(\mathrm{C}_{2} \mathrm{H}_{3} \mathrm{O}_{2}\right)_{2}(44.8 \mathrm{mg}$, $0.20 \mathrm{mmol}$ ) and 2-di-t-butylphosphino-3,4,5,6-tetramethyl-2' $4^{\prime}, 6^{\prime}$ tri-propylbi-phenyl (Xphos, $0.14 \mathrm{~g}, 0.40 \mathrm{mmol}$ ) were thoroughly mixed in a $100 \mathrm{~mL}$ flask under nitrogen protection and then heated in the oil bath at $70^{\circ} \mathrm{C}$ for $4 \mathrm{~h}$ with vigorous stirring. The mixture was then extracted with $\mathrm{CH}_{2} \mathrm{Cl}_{2}(3 \times 25 \mathrm{~mL})$. The combined organic layer was dried with anhydrous $\mathrm{Na}_{2} \mathrm{SO}_{4}$. After removal of the solvent by rotary evaporation, the residue was purified by ethanol to give the title compound as a white solid (1.29 g, yield: 95.3\%). ${ }^{1} \mathrm{H}$ NMR (400 MHz, $\left.\mathrm{CDCl}_{3}\right) \delta 8.60(\mathrm{~s}, 1 \mathrm{H})$, $8.18(\mathrm{~d}, J=7.6 \mathrm{~Hz}, 2 \mathrm{H}), 8.01(\mathrm{dd}, J=11.8,5.0 \mathrm{~Hz}, 2 \mathrm{H}), 7.95(\mathrm{~d}, J=$ $7.6 \mathrm{~Hz}, 1 \mathrm{H}), 7.72(\mathrm{~d}, J=6.6 \mathrm{~Hz}, 1 \mathrm{H}), 7.62(\mathrm{dd}, J=12.8,8.4 \mathrm{~Hz}, 2 \mathrm{H})$, $7.50-7.43(\mathrm{~m}, 4 \mathrm{H}), 7.37(\mathrm{~d}, J=7.8 \mathrm{~Hz}, 1 \mathrm{H}), 7.31-7.27(\mathrm{~m}, 1 \mathrm{H})$.

3-(Dibenzo[b,d]furan-4-yl)-9-(4,6-diphenyl-1,3,5-triazin-2-yl)9H-carbazole (BFTC). A mixture of 3-(dibenzo[b, $d]$ furan-4-yl)$9 H$-carbazole $(1.0 \mathrm{~g}, 3.0 \mathrm{mmol})$, dimethyl formamide $(20 \mathrm{~mL})$ was thoroughly mixed in a $100 \mathrm{~mL}$ flask under nitrogen protection and then sodium hydride was added $(3.6 \mathrm{mg}, 0.15$ $\mathrm{mmol}$ ). The mixture was stirred for $15 \mathrm{~min}$. After that, 2-chloro4,6-diphenyl-1,3,5-triazine $(0.80 \mathrm{~g}, 3.0 \mathrm{mmol})$ was added at room temperature with vigorous stirring. The mixture was poured into water and the precipitate was collected by filtration. The residue was recrystallized from ethanol and the title compound was obtained as a light yellow solid (1.58 g, 
yield: $93.5 \%) .{ }^{1} \mathrm{H}$ NMR spectra of the target compound was not obtained for its poor solubility in common solvent. HRMS (ESI, $m / z$ ) calculated for $\mathrm{C}_{39} \mathrm{H}_{24} \mathrm{~N}_{4} \mathrm{O}: 565.2028$, found $[\mathrm{M}]^{+}: 565.2050$. Anal. calcd for $\mathrm{C}_{39} \mathrm{H}_{24} \mathrm{~N}_{4} \mathrm{O}$ : $\mathrm{C} 82.96, \mathrm{H} 4.28, \mathrm{~N}$ 9.92. Found: $\mathrm{C}$ 82.61, H 3.90, N 9.72.

3-(Dibenzo $[\boldsymbol{b}, \boldsymbol{d}]$ thiophen-4-yl)-9H-carbazole (5). The title compound was synthesized according to the similar procedure to 3 , with the addition of dibenzo[ $[b, d]$ thiophen-4-ylboronic acid and the title compound was obtained as a white solid (yield: 97.2\%). ${ }^{1} \mathrm{H}$ NMR (400 MHz, $\left.\mathrm{CDCl}_{3}\right) \delta 8.45$ (d, $\left.J=1.6 \mathrm{~Hz}, 1 \mathrm{H}\right)$, 8.24-8.11 (m, 4H), 7.85-7.80 (m, 2H), 7.59 (dd, $J=10.4,6.4 \mathrm{~Hz}$, $3 \mathrm{H}), 7.49-7.44(\mathrm{~m}, 4 \mathrm{H}), 7.28$ (dd, $J=7.8,1.6 \mathrm{~Hz}, 1 \mathrm{H})$.

3-(Dibenzo[b, $d]$ thiophen-4-yl)-9-(4,6-diphenyl-1,3,5-triazin-2yl)-9H-carbazole (BTTC). The title compound was synthesized according to the similar procedure to BFTC, with the addition of intermediate $\mathbf{5}$ and the title compound was achieved as a white solid (yield: $89.7 \%$ ). ${ }^{1} \mathrm{H}$ NMR spectra of the target compound was not obtained for its poor solubility in common solvent. HRMS (ESI, $m / z$ ) calculated for $\mathrm{C}_{39} \mathrm{H}_{24} \mathrm{~N}_{4} \mathrm{~S}$ : 581.1800, found $[\mathrm{M}]^{+}$: 581.1796. Anal. calcd for $\mathrm{C}_{39} \mathrm{H}_{24} \mathrm{~N}_{4} \mathrm{~S}$ : C 80.67, H 4.17, N 9.65. Found: C 80.54, H 3.66, N 9.51.

\section{OLEDs fabrication}

All devices were encapsulated in a $\mathrm{N}_{2}$ purged glove box connected to the evaporator after the fabrication for device electroluminescence characterization. The ITO/glass substrate was cleaned sequentially by detergent, de-ionized water and ethanol. Then the ITO/glass was treated by oxygen $\left(\mathrm{O}_{2}\right)$ and polymerized fluorocarbon ( $\mathrm{CFx}$ ) plasma before loading into a 10-source evaporator, with a base pressure of $5.0 \times 10^{-4} \mathrm{~Pa}$, for device fabrication. Organic layers were deposited on the indium-tin-oxide (ITO)/glass substrate by thermal evaporation.

\section{Conclusion}

In summary, two novel bipolar host materials, BFTC and BTTC are synthesized and characterized, and electroluminescence performance of green PhOLED based on those two host materials are investigated. Eventually, BTTC demonstrates its promising potential as a desirable host material for green PHOLED with a high $T_{\mathrm{d}}$ of $452{ }^{\circ} \mathrm{C}$. The green PhOLEDs based on those host materials with the structure of ITO/PEDOT:PSS/ TAPC/TCTA/host: $\operatorname{Ir}(\mathrm{ppy})_{3}$ (8 wt\%)/TPBi/LiF/Al show superior electroluminescence performance, with the turn-on voltage of $3.4 \mathrm{~V}$ and maximum current, power and external quantum efficiency of $69.3 \mathrm{~cd} \mathrm{~A}^{-1}, 54.2 \mathrm{~lm} \mathrm{~W}^{-1}$ and $21.9 \%$, respectively.

\section{Notes and references}

1 M. A. Baldo, D. F. O'Brien, Y. You, S. Sibley, M. E. Thompson and S. R. Forrest, Nature, 1998, 395, 151.

2 K. Walzer, B. Maennig, M. Pfeiffer and K. Leo, Chem. Rev., 2007, 107, 1233-1271.

3 J. H. Huang, J. H. Su, X. Li, M. K. Lam, K. M. Fung, H. H. Fan, K. W. Cheah, C. H. Chen and H. Tian, J. Mater. Chem., 2011, 21, 2957.
4 C. W. Tang and S. A. VanSlyke, Appl. Phys. Lett., 1987, 51, 913.

5 J. H. Huang, J. H. Su and H. Tian, J. Mater. Chem., 2012, 22, 10977.

6 B. W. D'Andrade and S. R. Forrest, Adv. Mater., 2004, 16, 1585-1595.

7 S. Chen, L. Deng, J. Xie, L. Peng, L. Xie, Q. Fan and W. Huang, Adv. Mater., 2010, 22, 5227-5239.

8 Y. Tao, C. Yang and J. Qin, Chem. Soc. Rev., 2011, 40, 2943-2970.

9 Y. Y. Lyu, J. Kwak, W. S. Jeon, Y. Byun, H. S. Lee, D. Kim, C. Lee and K. Char, Adv. Funct. Mater., 2009, 19, 420.

10 P. I. Shih, C. H. Chien, C. Y. Chuang, C. F. Shu, C. H. Yang, J. H. Chen and Y. Chi, J. Mater. Chem., 2007, 17, 1692.

11 Y. Tao, S. Gong, Q. Wang, C. Zhong, C. Yang, J. Qin and D. Ma, Phys. Chem. Chem. Phys., 2010, 12, 2438.

12 F. M. Hsu, C. H. Chien, C. F. Shu, C. H. Lai, C. C. Hsieh, K. W. Wang and P. T. Chou, Adv. Funct. Mater., 2009, 19, 2834.

13 Y. Tao, Q. Wang, C. Yang, J. Qin and D. Ma, ACS Appl. Mater. Interfaces, 2010, 2, 2813.

14 X. L. Li, X. Ouyang, M. Liu, Z. Ge, J. Peng, Y. Cao and S. J. Su, J. Mater. Chem. C, 2015, 3, 9233.

15 K. P. Guo, H. D. Wang, Z. X. Wang, C. F. Si, C. Y. Peng, G. Chen, J. H. Zhang, G. F. Wang and B. Wei, Chem. Sci., 2017, DOI: 10.1039/c6sc03008d.

16 S. Lee, K. H. Kim, D. Limbach, Y. S. Park and J. J. Kim, Adv. Funct. Mater., 2014, 24, 6074.

17 R. Keruckiene, D. Volyniuk, J. Ostrauskaite, L. Peciulyte, J. V. Grazulevicius, S. V. Kostjuk and A. Lazauskas, Dyes Pigm., 2016, 137, 58-68.

18 G. J. Tian, X. Wei, N. Xiang, J. H. Huang, J. Cao, Z. X. Wang, J. H. Zhang and J. H. Su, RSC Adv., 2016, 6, 51575-51582.

19 Y. Chen, W. Q. Liang, W. H. Choi, J. H. Huang, Q. C. Dong, F. R. Zhu and J. H. Su, Dyes Pigm., 2015, 123, 196-203.

20 F. Dumur, Org. Electron., 2015, 25, 345-361.

21 D. R. Lee, C. W. Lee and J. Y. Lee, J. Mater. Chem. C, 2014, 2, 7256.

22 H. F. Chen, S. J. Yang, Z. H. Tsai, W. Y. Huang, T. C. Wang and K. T. Wong, J. Mater. Chem., 2009, 19, 8112-8118.

23 G. Hughes and M. R. Bryce, J. Mater. Chem., 2005, 15, 94.

24 S. M. Kim, S. Y. Byeon, S. H. Hwang and J. Y. Lee, Chem. Commun., 2015, 51, 10672-10675.

25 D. Wanger, S. T. Hoffmann, U. Heinemeyer, I. Munster, A. Kohler and P. Strohriegl, Chem. Mater., 2013, 25, 3758-3765.

26 S. J. Su, C. Cai, J. Takamatsu and J. Kido, Org. Electron., 2012, 13, 1937-1947.

27 C. H. Chang, M. C. Kuo, W. C. Lin, Y. T. Chen, K. T. Wong, S. H. Chou, E. Mondal, R. C. Kwong, S. Xia, T. Nakagawa and C. Adachi, J. Mater. Chem., 2012, 22, 3832.

28 J. S. Kang, T. R. Hong, H. J. Kim, Y. H. Son, R. Lampande, B. Y. Kang, C. Lee, J. K. Bin, B. S. Lee, J. H. Yang, J. W. Kim, S. Park, M. J. Cho, J. H. Kwon and D. H. Choi, J. Mater. Chem. C, 2016, 4, 4512.

29 M. Romain, S. Thiery, A. Shirinskaya, C. Declairieux, D. Tondelier, B. Geffroy, O. Jeannin, J. Rault-Berthelot, R. Metivier and C. Poriel, Angew. Chem., Int. Ed., 2014, 54, 1176.

30 J. Li, T. Zhang, Y. Liang and R. Yang, Adv. Funct. Mater., 2013, 23, 619-628. 